\title{
Call for a California Coccidioidomycosis Consortium to Face the Top Ten Challenges Posed by a Recalcitrant Regional Disease
}

\author{
George R. Thompson III - David A. Stevens · Karl V. Clemons · Josh Fierer • \\ Royce H. Johnson · Jane Sykes • George Rutherford • Michael Peterson • \\ John W. Taylor $\cdot$ Vishnu Chaturvedi
}

Received: 18 April 2014 / Accepted: 17 September 2014/Published online: 16 October 2014

(C) Springer Science+Business Media Dordrecht 2014

\begin{abstract}
Coccidioidomycosis ('Valley Fever'), caused by the inhalation of the fungus Coccidioides, remains a recalcitrant health problem in large parts of California. The incidence and severity of the disease continues to rise in many parts of the state. In this manuscript, we highlight unanswered questions about the disease. Specifically, the extent of disease burden,
\end{abstract}

G. R. Thompson III

Department of Medical Microbiology and Immunology, Coccidioidomycosis Serology Laboratory, University of California, Davis, Davis, CA, USA

e-mail: grthompson@ucdavis.edu

G. R. Thompson III

Division of Infectious Diseases, Department of Internal Medicine, University of California, Davis, Davis, CA, USA

D. A. Stevens - K. V. Clemons · V. Chaturvedi $(\bowtie)$ California Institute for Medical Research, San Jose, CA, USA

D. A. Stevens

Stanford University School of Medicine, Stanford, CA, USA

J. Fierer

Division of Infectious Diseases, Department of Internal Medicine, University of California, San Diego,

San Diego, CA, USA

\section{R. H. Johnson}

Division of Infectious Diseases, Department of Internal Medicine, David Geffen School of Medicine, University of California, Los Angeles, CA, USA genetic determinants of host susceptibility, diagnostic and treatment guidelines, natural reservoirs of the pathogens, antifungal drug resistance, and fungal determinants of mild or severe disease are all areas awaiting in depth investigations. We also recommend establishment of a California Coccidioidomycosis Registry to improve clinical care and translational research.

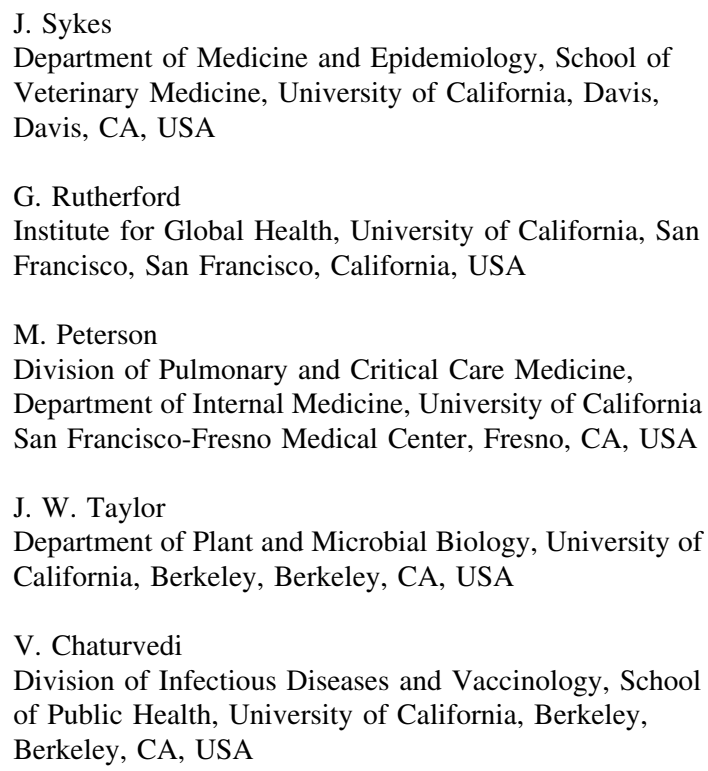


Keywords Coccidioidomycosis - Coccidioides · Valley fever $\cdot$ Epidemiology $\cdot$ Emerging infectious diseases

\section{Introduction}

Coccidioidomycosis, commonly known as San Joaquin Valley Fever or Valley Fever, has been recognized as an endemic disease in California, particularly its central valley, for more than a century (Fig. 1) [1]. Despite breakthroughs in the middle of the last century, many aspects of coccidioidomycosis and the pathogens (Coccidioides immitis and Coccidioides posadasii) have remained enigmatic [2-4]. Paralleling the marked increase in the incidence of the disease in Arizona, in the last decade, there has been an upsurge in the incidence of the disease in both endemic and nonendemic areas of California. As a result, there has been an alarming increase in the rates of coccidioidomycosis in children [5], incarcerated populations [6], and there
Fig. 1 California countyspecific coccidioidomycosis incidence rates, 2011 (Courtesy of California Department of Public Health)

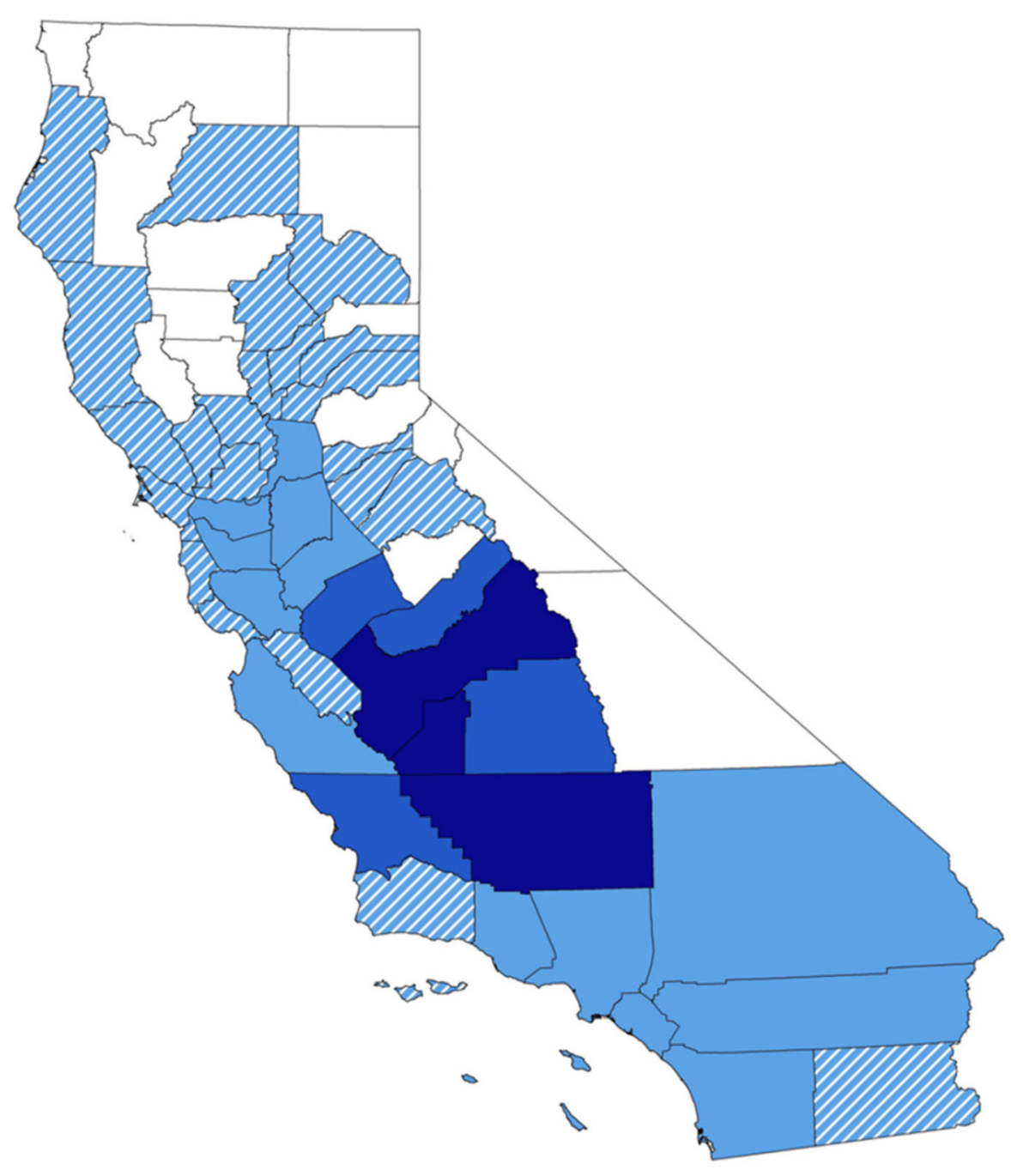

Cases per 100,000 population

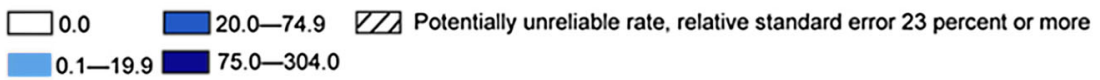


Fig. 2 Numbers and annual rates of initial and subsequent coccidioidomycosisassociated hospitalizations $(N=25,217)$ by year of admission, California, 2000-2011. (Reproduced with permission) [7]

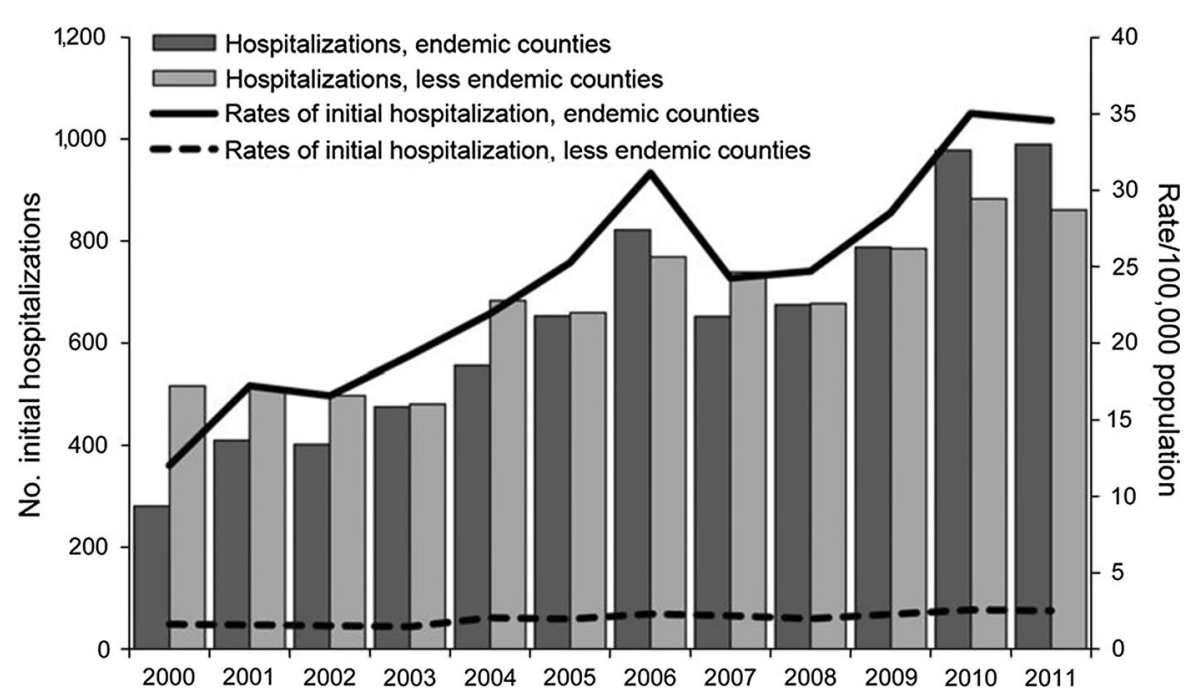

are reports of higher rates of hospitalizations for coccidioidomycosis [7]. Clearly, the epidemic is taking a turn for the worse, which should require sustained interventions from medical and public health communities. This opinion article highlights the major outstanding questions that must be addressed to improve disease outcomes and to devise preventive strategies.

How Serious is the Problem

of Coccidioidomycosis in California?

Earlier reports have documented high morbidity and mortality due to coccidioidomycosis in persons with AIDS [8]. The incidence and severity in this population appears to have declined with the introduction of combination antiretroviral therapy [9]. However, the overall incidence of coccidioidomycosis in California has increased in the last two decades (Fig. 2).

In California, this increase first became apparent during the last decade when the annual incidence went from 2.5 per 100,000 during 1995-2000 to 8 per 100,000 in 2006 [10], increased further during 2010 and 2011 (14 per 100,000) [11]. The reasons for this increase remain unclear. Some have hypothesized that the increase may be, in part, an artifact of the greater use of non-specific diagnostic tests such as the Meridian EIA test that has a high false-positivity rate for IgM antibody. Other factors for the observed changes could include improved disease awareness by patients and physicians alike, increased travel, or population growth in endemic areas, and growth of the "at-risk" population [12, 13]. Alternative or contributory factors such as increased spore dispersal due to environmental changes (i.e., temperature, moisture) [14] or increased construction accompanying population growth within the endemic region have also been proposed as explanations $[15,16]$. The severe drought conditions prevailing in California in last few years have yet to be investigated although historical data suggest a correlation between drought indices and the disease incidence. Continued surveillance and analysis of trends in the diagnosis of coccidioidomycosis seem prudent given the ongoing and increasing public health burden of this disease to better answer the question of how serious the burden of coccidioidomycosis is in the state of California.

Is Coccidioidomycosis Spreading into New Areas and Populations Within California?

There is a marked trend for the migration of California's population from coastal areas to inland counties [17]. Some of the areas into which the new migrants are moving were not known previously to be highly endemic for Coccidioides species. However, a high incidence of the disease is being reported from several "non-endemic" areas [18]. Therefore, it is reasonable to assume that the fungus is spreading within California. There is additional evidence that the range of the fungus has increased based on recent reports of coccidioidomycosis from Washington and Utah [14, 
19]. Additional studies carried out in Washington State have shown high-level soil colonization and genetic links between soil and patient isolates [9].

Coccidioidomycosis is known to pose higher risks to African-Americans and Filipino-Americans compared to the Caucasian population [20]. The ethnic mix of the new migrants is tilted toward Hispanics and Asians [21]. The risks to the new migrants for clinically apparent coccidioidomycosis appear increased, but this has not been precisely determined.

\section{Where are the Natural Habitats of Coccidioides in California?}

Knowledge about the natural reservoir is important for reducing exposure of humans to Coccidioides. Ecological research has focused on the saprophytic soil phase and is aimed at identifying environmental factors that associate with the presence of Coccidioides species, including wind, precipitation, temperature variation, and a predilection for alkaline sandy soil, commonly about 10-30 $\mathrm{cm}$ beneath the surface [22]. However, some studies have documented that Coccidioides is more easily isolated from two genera of small mammals, pocket mice (Perognathus spp.) and kangaroo rats (Dipodomyces spp.) [23], than it is from soil $[24,25]$. Additional rodent species might also he involved most likely the desert woodrat found seropositive for coccidioidal antibody in Baja California, Mexico [26].

Interestingly, comparative genomics has shown that Coccidioides species lack genes for several enzymes widely used by fungi to digest plant cell walls, but they have expanded gene families of enzymes that digest animal protein [27]. These data suggest that Coccidioides may not be primarily saprophytic in soil, but saprozoic in the carcasses of animals infected with Coccidioides spp. when the animals were alive [23, 27]. Thus, it may be possible to assess the hazard of humans contracting coccidioidomycosis in a particular geographic area by surveying Perognathus and Dipodomys species for the presence of Coccidioides species either by necropsies with culture directly or by doing serology. So, these two animal species might serve as sentinels for the presence of Coccidioides in the local environment. Any surveillance activities in this area will be a challenging endeavor as the two animals are currently on the endangered list by the US Fish and Wildlife Service.
What Host Genetic Factors Predispose Certain Individuals and Ethnic Groups to Higher Risks for Coccidioides Infections?

The widely disparate clinical course of coccidioidomycosis has long been recognized [3]. The inter-patient variability of coccidioidomycosis is likely secondary to immunogenetic differences in the host response to fungal invasion. Mouse models of infections have identified TLR2 [28], TLR4, Dectin-1 [29, 30], and hypoxia-inducible factor $1 \mathrm{~A}$ (HIF1A) [31] as contributory to outcomes and the severity of disease, yet human studies have lagged behind [32]. Genetic influences, such as the ABO blood group type and human leukocyte antigen (HLA) alleles, may play a role. For example, the HLA class II DRB1*1301 allele has been associated with the development of severe, disseminated disease [33, 34]. Alternatively, these markers may only be surrogate markers for at-risk ethnic populations [35]. Mutations in the IFN- $\gamma /$ IL12 pathway have also been found in a few patients with disseminated infections; however, these have not been noted in the majority of patients with severe coccidioidomycosis [36, 37]. Furthermore, elucidation of the immunogenetic mechanism(s) responsible for the dissemination could offer prognostic information. Those with low-risk genetic features could potentially avoid the lengthy clinical follow-up, laboratory testing, and unnecessary radiographic imaging. Those with high-risk genetic features would receive more aggressive antifungal therapy upfront and benefit from preemptive antifungal treatment prior to the morbidity that often results when disseminated infection is encountered.

The advent of genome-wide association studies now allows this question to be answered in a costefficient manner [38]. Following the identification of host factors predisposing to either symptomatic infection or coccidioidal dissemination, patients could be "screened" for heightened susceptibility to coccidioidomycosis. There is a high burden of disease within the prison system, the US military, and nonimmune individuals who are working or traveling to an endemic region. If a genetic marker is identified conferring susceptibility to coccidioidomycosis, these groups would undoubtedly benefit from targeted screening. Avoidance of exposure by allocation to alternative prison sites, military installations, or places and types of employment could then be pursued, or in some cases, antifungal prophylaxis is provided if 
short-term exposure is unavoidable. Ideally, a genetic test will become available to allow for testing of individual for increased susceptibility to Coccidioides spp.

Are Current Diagnostic Tests Adequate

for Sensitive and Specific Detection of Coccidioidomycosis?

The mainstay of coccidioidal diagnostics remains serology using the immunodiffusion, complement fixation, or EIA-based methods. Currently, the available tests are useful for the detection of antibody but not the pathogen. IgM antibodies are detectable in $53 \%$ of patients at 1 week after the onset of symptoms, $80 \%$ at 2 weeks, and $>91 \%$ at 3 weeks [39]. The negative serological results during early phases of infection and in immunosuppressed patients who are unable to manifest an antibody response have prompted interest in Coccidioides antigen testing [40-42], and a commercial coccidioidal antigen test has become available. This test has proven useful only in a case series with widely disseminated infection [43] and has a poor sensitivity in veterinary samples [44]. Ongoing work will likely further clarify the role of coccidioidal antigen testing in the diagnosis of coccidioidal infections [45].

A significant problem in the endemic area is distinguishing coccidioidal granulomata from lung cancer. The use of PCR and antigen testing from BAL samples is currently under evaluation [46, 47]. If proven to display sufficient sensitivity/specificity, these platforms may prove useful and could avoid unnecessary surgery. Additionally, continued improvements in radiographic imaging may someday allow for the avoidance of invasive diagnostic procedures. Utilizing current CT scans, the fraction of concerning lung nodules that require invasive studies to differentiate from lung cancer remains at $33 \%$, the same fraction as reported in 1986 using chest X-ray imaging [48]. Newer modalities such as PET-CT have been incompletely studied in the evaluation of coccidioidomycosis and results thus far have been unsatisfactory with frequent false-positives and false-negatives alike.

The recent availability of antigen for skin testing patients also represents a potential advance in the care of patients with coccidioidomycosis [49]. Although this test plays a limited role in the treatment of patients, it does allow for the identification of previously exposed individuals and would serve a useful purpose in identifying those immune to Coccidioides spp. prior to travel or housing (e.g., prisoners, military personnel etc.) within the endemic regions.

How Relevant are Current Guidelines About When and How to Treat Coccidioidomycosis Patients with Primary Infection?

How best to manage symptomatic patients with primary coccidioidal pneumonia remains a contentious issue. Some experts in the field recommend no treatment for most patients with primary infection but rather to manage patients by periodic reassessment of symptoms and radiographic findings to assure resolution of symptoms without antifungal treatment. They point out that most patients have an illness that will run its course without specific treatment, and "watchful waiting" avoids the costs and potential toxicity of antifungal treatment. Early treatment does not clearly avert later complications [50], and recent serologic observations have shown treatment may alter the protective host response that the infection generates $[51,52]$.

Experts who propose treatment for all symptomatic patients hypothesize that the treatment reduces the severity and duration of symptoms. They also suggest that the toxicity and costs associated with antifungals are overstated or based on outdated experience when amphotericin B deoxycholate was the only available antifungal agent. In their experience, the costs and toxicity of currently available antifungals are quite low [53]. Finally, the patients expect at least a trial of antifungal therapy if they are symptomatic, and a potentially efficacious agent is readily available.

A double-blind placebo controlled trial evaluating the effects of antifungal therapy on the course of those with proven or probable primary coccidioidal pneumonia has been proposed and is currently in the planning stages. It will be sponsored by the National Institute of Health (NIH) in collaboration with the Centers for Disease Control and Prevention (CDC) [54]. It is critically important to understand whether treatment of primary coccidioidal infection changes the course of infection with diminishment or more rapid resolution of patient symptoms. Given that there are no prospective trials evaluating the response to antifungal therapy in primary coccidioidal pneumonia, this study offers us a unique and important opportunity 
to potentially improve patient outcomes using a symptom-based endpoint.

\section{Is Drug Resistance Responsible for 'Relapsing' or Refractory Coccidioidomycosis?}

To date, a single clinical treatment failure associated with elevated fluconazole MICs of the isolate has been published [55]. Notably, fluconazole MICs and MFCs (minimum fungicidal concentrations) that exceed achievable blood levels with ordinary dosing regimens are common [56]. The epidemiology and mechanism(s) of resistance in such isolates, and which alternative agents to use when these isolates are encountered, have not been determined. It is conceivable that isolates of Coccidioides exhibit resistance mechanisms seen in other fungi: target site change (ERG11) or induction of drug efflux pumps (MDR1 etc.), but definitive studies remain to be conducted. Testing of environmental isolates has been limited, although no environmental isolates with high MICs have been reported to date.

Are Strains of Coccidioides Genetically Different in Mild and Serious Infections? And What Fungal Elements Allow Coccidioides to Survive and Spread Within the Host?

A subset of Coccidioides infections progresses to serious, and in some cases, systemic disease. A longheld belief in the scientific community attributes this variation to host factors. However, it is also possible that genetic differences in Coccidioides strains influence the outcome of infection. Recent work with other chronic granulomatous diseases, most notably tuberculosis, has led to the recognition of a subset of pathogenic strains that cause more serious infections due to enhanced expression of virulence determinants [57]. Similar genome-wide association studies (GWAS) in other fungi including pathogens have revealed important understanding of virulence mechanisms [58-60]. GWAS is a promising approach to understand genetic basis of disease severity in Coccidioides strains.

The knowledge about Coccidioides structural-functional elements ('virulence factors') that determine its unique pathogenic attributes is fragmentary. Although many genes and enzymes critical to pathogenic processes have been identified, they broadly resemble the virulence factors of other pathogenic fungi. Thus, we know about the virulence factors that Coccidioides species share with other fungal pathogens, but it will be equally important to identify Coccidioides-specific virulence factors that determine organ tropism, persistence, and latency in the human host [61]. These specific fungal components could yield a treasure trove of targets for developing diagnostic reagents, vaccine constituents, and therapeutic agents.

What is the Status of a Coccidioidal Vaccine?

It has been recognized since the 1940s that individuals who recovered from coccidioidomycosis have durable immunity to reinfection, with the exception of severely immunosuppressed patients [62]. The observations suggest that the preventive immunization may confer sufficient immunity to protect against initial infection. Early trials using formalin-inactivated whole organisms found that the immunization was associated with high incidence of local and systemic side effects, limiting the number of spherules that could be injected. These trials, while suggestive, did not find that killed organism could induce a sufficiently protective response [63, 64].

More recently efforts have focused on individual antigen [65-69] and live-attenuated vaccines [70]. Several antigens have been identified that can induce protective immunity to parenteral and respiratory challenge in animal models. These have not been able to be scaled to trials, at least in part because issues of what constitutes a protective immune response, and hence what could serve as a surrogate marker for protection in trials, have not been fully resolved. It is known that immunity is primarily cellular and utilizes a Th1 response mediated by IFN- $\gamma$ and IL-12activated macrophages although humoral immunity also appears to be important [71]. A concerted effort at vaccine development spanned several laboratories from 1998 to 2012 and was unable to bring a commercially viable vaccine candidate to trial for either human or veterinary use $[72,73]$. Nonetheless, essential components of the immune response were elucidated, and a great deal has been learned regarding immune responses to various coccidioidal proteins and to attenuated strains. These data will be valuable in moving future vaccine development efforts forward. 
How Would the Establishment of a California Coccidioidomycosis Registry Promote Better Clinical Care and More Translational Research?

An Internet-based California Coccidioidomycosis Registry is urgently needed to combine and organize data contributed by physicians, veterinarians, researchers, epidemiologists, and policy makers. The registry would prove valuable to highlight the practices that lead to the improvements in patient outcomes. It would also augment post-marketing surveillance of new antifungal medications and diagnostic tests. An online database would help promote rapid communications among various stakeholders such as physicians, public health officials, and policy makers, and it could enable the creation of a repository of DNA and other clinical samples for genotypephenotype association studies, which would greatly enhance translational research. A registry could be organized rather quickly using established norms for other disease registries supported by the NIH and nonprofit organizations.

\section{Conclusions}

We earnestly hope that this brief overview will convince the readers that coccidioidomycosis poses a serious problem for many residents of California. It is not a viable option for people at risk to leave the high incidence areas as their livelihoods depend upon local agriculture and industry. As observed with other regional diseases, a renewed focus on research and development is the only route to find better solutions for the clinical and environmental challenges posed by Coccidioides species. Recently, the federal authorities have acknowledged the severity of the problem by announcing a clinical trial. This effort should be enhanced and maintained for the near future. Additionally, public and private institutions in California must commit their enormous academic and financial resources to finding better solutions for coccidioidomycosis.

Acknowledgments We thank Drs. Farzaneh Tabnak and Duc Vugia, Infectious Diseases Branch, DCDC, CID California Department of Public Health for providing a copy of Fig. 1.

\section{References}

1. Galgiani JN, Ampel NM, Blair JE, et al. Coccidioidomycosis. Clin Infect Dis. 2005;41(9):1217-23.

2. Smith CE. Epidemiology of acute coccidioidomycosis with erythema nodosum ("San Joaquin" or "Valley Fever"). Am J Public Health Nation's Health. 1940;30(6):600-11.

3. Smith CE, Saito MT, Simons SA. Pattern of 39,500 serologic tests in coccidioidomycosis. J Am Med Assoc. 1956;160(7):546-52.

4. Willett FM, Weiss A. Coccidioidomycosis in southern California: report of a new endemic area with a review of 100 cases. Ann Intern Med. 1945;23(3):349-75.

5. McCarty JM, Demetral LC, Dabrowski L, Kahal AK, Bowser AM, Hahn JE. Pediatric coccidioidomycosis in central California: a retrospective case series. Clin Infect Dis. 2013;56(11):1579-85.

6. Pappagianis D. Coccidioidomycosis serology L. coccidioidomycosis in California state correctional institutions. Ann NY Acad Sci. 2007;1111:103-11.

7. Sondermeyer G, Lee L, Gilliss D, Tabnak F, Vugia D. Coccidioidomycosis-associated hospitalizations, California, USA, 2000-2011. Emerg Infect Dis. 2013;19(10):1590-7.

8. Flaherman VJ, Hector R, Rutherford GW. Estimating severe coccidioidomycosis in California. Emerg Infect Dis. 2007;13(7):1087-90.

9. Masannat FY, Ampel NM. Coccidioidomycosis in patients with HIV-1 infection in the era of potent antiretroviral therapy. Clin Infect Dis. 2010;50(1):1-7.

10. CDC. Increase in coccidioidomycosis-California. MMWR 2009;58:105-9.

11. CDC. Increase in reported coccidioidomycosis-United States, 1998-2011. MMWR 2013;62(12):217-21.

12. Ampel NM. What's behind the increasing rates of coccidioidomycosis in Arizona and California? Curr Infect Dis Rep. 2010;12(3):211-6.

13. Brown J, Benedict K, Park BJ, Thompson GR III. Coccidioidomycosis: epidemiology. Clin Epidemiol. 2013;5:18597.

14. Marsden-Haug N, Goldoft M, Ralston C, et al. Coccidioidomycosis acquired in Washington State. Clin Infect Dis. 2013;56(6):847-50.

15. Park BJ, Sigel K, Vaz V, et al. An epidemic of coccidioidomycosis in Arizona associated with climatic changes, 1998-2001. J Infect Dis. 2005;191(11):1981-7.

16. Das R, McNary J, Fitzsimmons K, et al. Occupational coccidioidomycosis in California: outbreak investigation, respirator recommendations, and surveillance findings. J occup environ med. 2012;54(5):564-71.

17. Demographic Research Unit California Department of Finance 915 L Street Sacramento, CA 95814. http://www.dof. ca.gov/research/demographic/. Accessed November 2011

18. Laniado-Laborin R. Expanding understanding of epidemiology of coccidioidomycosis in the Western hemisphere. Ann N Y Acad Sci. 2007;1111:19-34.

19. Centers for Disease C, Prevention. Coccidioidomycosis in workers at an archeologic site-Dinosaur National Monument, Utah, June-July 2001. MMWR Morb Mortal Wkly Rep. 2001;50(45):1005-8. 
20. Huang JY, Bristow B, Shafir S, Sorvillo F. Coccidioidomycosis-associated Deaths, United States, 1990-2008. Emerg Infect Dis. 2012;18(11):1723-8.

21. Current Population Survey: California Two-Year Average Series. March 2000-2011 Data Demographic Research Unit, California Department of Finance, Sacramento, CA.

22. Fisher FS, Bultman MW, Johnson SM, Pappagianis D, Zaborsky E. Coccidioides niches and habitat parameters in the southwestern United States: a matter of scale. Ann NY Acad Sci. 2007;1111:47-72.

23. Emmons CW, Ashburn LL. The isolation of Haplosporangium parvum $n$. sp. and Coccidioides immitis from wild rodents. Their relationship to coccidioidomycosis. Public Health Rep. 1942;57(46):1715-27.

24. Maddy KT, Crecelius HG. Establishment of Coccidioides immitis in negative soil following burial of infected animals and animal tissues. In: Ajello L, editor. Coccidioidomycosis. Tucson: University of Arizona Press; 1965. p. 309-12.

25. Greene DR, Koenig G, Fisher MC, Taylor JW. Soil isolation and molecular identification of Coccidioides immitis. Mycologia. 2000;92(3):406-10.

26. Catalan-Dibene J, Johnson SM, Eaton R, et al. Detection of coccidioidal antibodies in serum of a small rodent community in Baja California, Mexico. Fungal biol. 2014;118(3): 330-9.

27. Sharpton TJ, Stajich JE, Rounsley SD, et al. Comparative genomic analyses of the human fungal pathogens Coccidioides and their relatives. Genome Res. 2009;19(10): 1722-31.

28. Viriyakosol S, Fierer J, Brown GD, Kirkland TN. Innate immunity to the pathogenic fungus Coccidioides posadasii is dependent on Toll-like receptor 2 and Dectin-1. Infect Immun. 2005;73(3):1553-60.

29. Viriyakosol S, del Pilar Jimenez P, Gurney MA, Ashbaugh $\mathrm{ME}$, Fierer J. Dectin-1 is required for resistance to coccidioidomycosis in mice. MBio. 2013;4(1):e00597-12.

30. del Pilar Jimenez AM, et al. Viriyakosol S, Walls L. Susceptibility to Coccidioides species in C57BL/6 mice is associated with expression of a truncated splice variant of Dectin-1 (Clec7a). Genes Immun. 2008;9(4):338-48.

31. Woelk CH, Zhang JX, Walls L, et al. Factors regulated by interferon gamma and hypoxia-inducible factor 1A contribute to responses that protect mice from Coccidioides immitis infection. BMC Microbiol. 2012;12:218.

32. Thompson GR III. Pulmonary coccidioidomycosis. Semin Respir Crit Care Med. 2011;32(6):754-63.

33. Louie L, $\mathrm{Ng} \mathrm{S}$, Hajjeh R, et al. Influence of host genetics on the severity of coccidioidomycosis. Emerg Infect Dis. 1999;5(5):672-80.

34. Deresinski SC, Pappagianis D, Stevens DA. Association of ABO blood group and outcome of coccidioidal infection. Sabouraudia. 1979;17(3):261-4.

35. Vinh DC, Masannat F, Dzioba RB, Galgiani JN, Holland SM. Refractory disseminated coccidioidomycosis and mycobacteriosis in interferon-gamma receptor 1 deficiency. Clin Infect Dis. 2009;49(6):e62-5.

36. Sampaio EP, Hsu AP, Pechacek J, et al. Signal transducer and activator of transcription 1 (STAT1) gain-of-function mutations and disseminated coccidioidomycosis and histoplasmosis. J Allergy Clin Immunol. 2013;131(6):1624-34.
37. Vinh DC, Schwartz B, Hsu AP, et al. Interleukin-12 receptor beta1 deficiency predisposing to disseminated Coccidioidomycosis. Clin Infect Dis. 2011;52(4):e99-102.

38. Barreiro LB, Tailleux L, Pai AA, Gicquel B, Marioni JC, Gilad Y. Deciphering the genetic architecture of variation in the immune response to Mycobacterium tuberculosis infection. Proc Natl Acad Sci USA. 2012;109(4):1204-9.

39. Pappagianis D. Serologic studies in coccidioidomycosis. Semin Respir Infect. 2001;16(4):242-50.

40. Weiner MH. Antigenemia detected in human coccidioidomycosis. J Clin Microbiol. 1983;18(1):136-42.

41. Galgiani JN, Grace GM, Lundergan LL. New serologic tests for early detection of coccidioidomycosis. J Infect Dis. 1991;163(3):671-4.

42. Galgiani JN, Dugger KO, Ito JI, Wieden MA. Antigenemia in primary coccidioidomycosis. Am J Trop Med Hyg. 1984;33(4):645-9.

43. Durkin M, Connolly P, Kuberski T, et al. Diagnosis of coccidioidomycosis with use of the Coccidioides antigen enzyme immunoassay. Clin Infect Dis. 2008;47(8):e69-73.

44. Kirsch EJ, Greene RT, Prahl A, et al. Evaluation of Coccidioides antigen detection in dogs with coccidioidomycosis. Clin Vaccine Immunol : CVI. 2012;19(3):343-5.

45. Thompson GR III, Bays DJ, Johnson SM, Cohen SH, Pappagianis D, Finkelman MA. Serum (1- > 3)-beta-D-glucan measurement in coccidioidomycosis. J Clin Microbiol. 2012;50(9):3060-2.

46. Vucicevic D, Blair JE, Binnicker MJ, et al. The utility of Coccidioides polymerase chain reaction testing in the clinical setting. Mycopathologia. 2010;170(5):345-51.

47. Thompson GR, Sharma S, Bays DJ, et al. Coccidioidomycosis: adenosine deaminase levels, serologic parameters, culture results, and polymerase chain reaction testing in pleural fluid. Chest. 2013;143(3):776-81.

48. Forseth J, Rohwedder JJ, Levine BE, Saubolle MA. Experience with needle biopsy for coccidioidal lung nodules. Arch Intern Med. 1986;146(2):319-20.

49. Johnson R, Kernerman SM, Sawtelle BG, Rastogi SC, Nielsen HS, Ampel NM. A reformulated spherule-derived coccidioidin (Spherusol) to detect delayed-type hypersensitivity in coccidioidomycosis. Mycopathologia. 2012;174(5-6):353-8.

50. Ampel NM, Giblin A, Mourani JP, Galgiani JN. Factors and outcomes associated with the decision to treat primary pulmonary coccidioidomycosis. Clin Infect Dis. 2009;48(2): 172-8.

51. Galgiani JN. Elements of style in managing coccidioidomycosis. Clin Infect Dis 2013.

52. Thompson GR 3rd, Lunetta JM, Johnson SM, et al. Early treatment with fluconazole may abrogate the development of IgG antibodies in coccidioidomycosis. Clin Infect Dis. 2011;53(6):e20-4.

53. Available at: http://www2.costco.com/Pharmacy/DrugInfo. asp $\mathrm{x} p=1 \&$ SearchTerm $=\mathrm{a} \&$ Drug=FLUCONAZOLE. Accessed March 18th, 2013.

54. Collins FS. NIH Research and Valley Fever, National Institutes of Health Kern County Valley Fever Symposium-Public Forum September 23, 2013.

55. Kriesel JD, Sutton DA, Schulman S, Fothergill AW, Rinaldi MG. Persistent pulmonary infection with an azole-resistant Coccidioides species. Med mycol. 2008;46(6):607-10. 
56. Kamberi P, Sobel RA, Clemons KV, et al. Comparison of itraconazole and fluconazole treatments in a murine model of coccidioidal meningitis. Antimicrob Agents Chemother. 2007;51(3):998-1003.

57. Click ES, Moonan PK, Winston CA, Cowan LS, Oeltmann JE. Relationship between Mycobacterium tuberculosis phylogenetic lineage and clinical site of tuberculosis. Clin Infect Dis. 2012;54(2):211-9.

58. Dalman K, Himmelstrand K, Olson A, Lind M, BrandstromDurling M, Stenlid J. A genome-wide association study identifies genomic regions for virulence in the non-model organism Heterobasidion annosum s.s. PLoS One. 2013;8(1):e53525.

59. Palma-Guerrero J, Hall CR, Kowbel D, et al. Genome wide association identifies novel loci involved in fungal communication. PLoS Genet. 2013;9(8):e1003669.

60. Muller LA, Lucas JE, Georgianna DR, McCusker JH. Genome-wide association analysis of clinical vs. nonclinical origin provides insights into Saccharomyces cerevisiae pathogenesis. Mol Ecol. 2011;20(19):4085-97.

61. Cole GT, Xue JM, Seshan K, et al. Virulence mechanisms of Coccidioides. In: Heitman J, Filler SG, Edwards JE, Mitchell AP, editors. Molecular principles of fungal pathogenesis. Washington DC: ASM Press; 2006. p. 363-91.

62. Pappagianis D. Seeking a vaccine against Coccidioides immitis and serologic studies: expectations and realities. Fungal Genet Biol. 2001;32(1):1-9.

63. Pappagianis D, Levine HB. The present status of vaccination against coccidioidomycosis in man. Am $\mathrm{J}$ Epidemiol. 1975;102(1):30-41.

64. Pappagianis D. Evaluation of the protective efficacy of the killed Coccidioides immitis spherule vaccine in humans. The Valley Fever Vaccine Study Group. Am Rev Respir Dis. 1993;148(3):656-60.
65. Delgado N, Xue J, Yu JJ, Hung CY, Cole GT. A recombinant beta-1,3-glucanosyltransferase homolog of Coccidioides posadasii protects mice against coccidioidomycosis. Infect Immun. 2003;71(6):3010-9.

66. Ivey FD, Magee DM, Woitaske MD, Johnston SA, Cox RA. Identification of a protective antigen of Coccidioides immitis by expression library immunization. Vaccine. 2003;21(27-30):4359-67.

67. Johnson SM, Lerche NW, Pappagianis D, Yee JL, Galgiani JN, Hector RF. Safety, antigenicity, and efficacy of a recombinant coccidioidomycosis vaccine in cynomolgus macaques (Macaca fascicularis). Ann N Y Acad Sci. 2007;1111:290-300.

68. Shubitz LF, Yu JJ, Hung CY, et al. Improved protection of mice against lethal respiratory infection with Coccidioides posadasii using two recombinant antigens expressed as a single protein. Vaccine. 2006;24(31-32):5904-11.

69. Tarcha EJ, Basrur V, Hung CY, Gardner MJ, Cole GT. A recombinant aspartyl protease of Coccidioides posadasii induces protection against pulmonary coccidioidomycosis in mice. Infect Immun. 2006;74(1):516-27.

70. Xue J, Chen X, Selby D, Hung CY, Yu JJ, Cole GT. A genetically engineered live attenuated vaccine of Coccidioides posadasii protects $\mathrm{BALB} / \mathrm{c}$ mice against coccidioidomycosis. Infect Immun. 2009;77(8):3196-208.

71. Kirkland TN, Raz E, Datta SK. Molecular and cellular mechanisms of protective immunity to coccidioidomycosis. Vaccine. 2006;24(4):495-500.

72. Hector RF, Rutherford GW, Tsang CA, et al. The public health impact of coccidioidomycosis in Arizona and California. Int J Environ Res Public Health. 2011;8(4):1150-73.

73. Cole GT, Xue JM, Okeke CN, et al. A vaccine against coccidioidomycosis is justified and attainable. Med Mycol. 2004;42(3):189-216. 